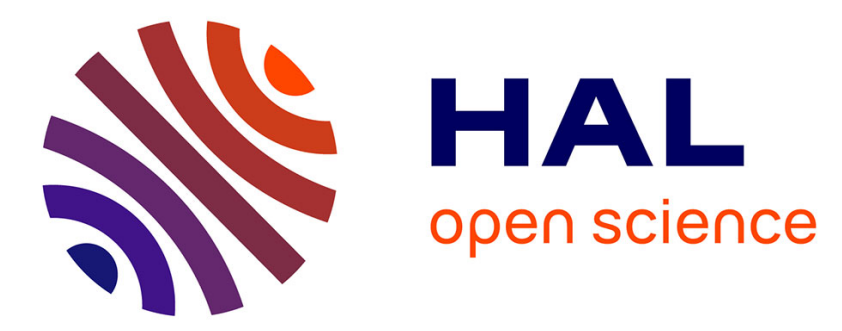

\title{
Change in the surface area and dissolution rate during acid leaching of phosphate particles at 25 degrees $\mathrm{C}$
}

A Mgaidi, F Ben Brahim, Driss Oulahna, M El Maaoui, John A. Dodds

\section{To cite this version:}

A Mgaidi, F Ben Brahim, Driss Oulahna, M El Maaoui, John A. Dodds. Change in the surface area and dissolution rate during acid leaching of phosphate particles at 25 degrees C. Industrial and engineering chemistry research, 2003, 42 (10), pp.2067-2073. 10.1021/ie020578c . hal-01626710

\section{HAL Id: hal-01626710 https://hal.science/hal-01626710}

Submitted on 7 Mar 2018

HAL is a multi-disciplinary open access archive for the deposit and dissemination of scientific research documents, whether they are published or not. The documents may come from teaching and research institutions in France or abroad, or from public or private research centers.
L'archive ouverte pluridisciplinaire HAL, est destinée au dépôt et à la diffusion de documents scientifiques de niveau recherche, publiés ou non, émanant des établissements d'enseignement et de recherche français ou étrangers, des laboratoires publics ou privés. 


\title{
Change in the Surface Area and Dissolution Rate during Acid Leaching of $\mathrm{Phosphate} \mathrm{Particles}$ at $25{ }^{\circ} \mathrm{C}$
}

\author{
A. Mgaidi, ${ }^{* D}$ F. Ben Brahim ${ }^{\mathrm{D} D}$. Oulahna, ${ }^{\mathrm{b}}$ M. El Maaoui, ${ }^{\mathrm{a}}$ and J.A Dodds \\ Industrial Inorganic Chem istry Laboratory, Chemistry Department, Faculty of Sciences, \\ Tunis 1060, Tunisia, and Laboratoire de Génie des Procédés des Solides Divisés, UMR CNRS 2392 , \\ Ecole des Mines d'Albi Carmaux, Campus Jarlard 81013 Albi, France
}

\begin{abstract}
This paper is part of a series of investigations into the reaction rate of acid dissolution of solids and particularly the influence of particle size distribution. In the case of acid dissolution of raw phosphate particles, preliminary results show that the reaction rate is significantly affected by the particle size distribution. In this paper, the dissolution into a $0.3 \mathrm{M} \mathrm{H}_{3} \mathrm{PO}_{4}$ solution of one size fraction $125-200 \mu \mathrm{m}\left(d_{\mathrm{p}}=162.5 \mu \mathrm{m}\right)$ prepared by sieving has been studied at $25^{\circ} \mathrm{C} \mathrm{using}$ a batch method. Experimental data were fitted to an empirical equation of the form $m / m_{\infty}=1$ $-\mathrm{e}^{-k t}$, where $m$ is the mass of phosphate dissolved at time $t$ and $m_{\infty}$ is the final mass of phosphate dissolved. The dissolution rate constant $k$ was found to be equal to $0.2118 \mathrm{~min}^{-1}$. Variation of the physical properties of the remaining solid with reaction time was studied. Experimental methods such as scanning electron microscopy (SEM), mercury porosimetry, argon adsorption/ desorption isotherms, and volume displacement using helium for the determination of the true density were used. As a result, a significant change in the Brunauer-Emmett-Teller surface area $\left(S_{\text {BET }}\right)$ occurred during the reaction. $S_{\text {BET }}$ was $16 \mathrm{~m}^{2} \cdot \mathrm{g}^{-1}$ at $t=0 \mathrm{~min}$, it reached a minimum value of $10 \mathrm{~m}^{2} \cdot \mathrm{g}^{-1}$ at $7 \mathrm{~min}$, and it increased again to $24 \mathrm{~m}^{2} \cdot \mathrm{g}^{-1}$ at $t=50 \mathrm{~min}$. Moreover, SEM observations revealed that phosphate particles dissolve beginning from their surface without any disintegration.
\end{abstract}

\section{Introduction}

In the production of high-grade phosphate fertilizers, the raw phosphate ore is converted into phosphoric acid and gypsum by a wet process using sulfuric acid. Production can be increased by reducing the particle size to decrease the reaction time, but rock fineness has to be sufficient to allow total recovery of $\mathrm{P}_{2} \mathrm{O}_{5}$ because large particles are more exposed to reaction blocking due to gypsum coating.

Although the overall reaction occurs between the phosphate ore and sulfuric acid, actually the phosphate particles are first dissolved in a phosphoric acid medium. The liberated calcium ions react immediately with sulfate anions to give calcium sulfate precipitates. Usually a merchant phosphate presents particle size distributions varying from $40-70 \mu \mathrm{m}$ to $2 \mathrm{~mm}$ with about 50 mass $\%$ over $125 \mu \mathrm{m}$.

In previous works, ${ }^{12}$ we obtained the following results:

1. Gas adsorption/desorption isotherm analysis revealed that the raw particles are porous and the mesoporosity increases during the dissolution progress.

2. $\mathrm{Ca}^{2+}$ ion diffusion, from the surface of the ore into the bulk of the solution, is the limiting-rate step of dissolution.

3. Mass-transfer coefficient of $\mathrm{Ca}^{2+}$ into solution is equal to $3 \times 10^{-3} \mathrm{~m} \cdot \mathrm{s}^{-1}$.

4. Van der Sluis et al.'s model ${ }^{3}$ gives a good prediction of the dissolution rate into concentrated and diluted phosphoric acid solutions.
Although there is a wide range of literature dealing with the dissolution kinetics of phosphate ores, very few authors have attempted to relate the kinetic rates to the solid texture. Evidence indicates that this relation is very important. So, according to Becker, ${ }^{4}$ North Carolina rock, which is a porous ore, reaches more than $99 \%$ decomposition within 2 min of dissolution. However, Kola rock, which is a nonporous ore $\left(S_{\mathrm{BET}}<0.1\right.$ $\mathrm{m}^{2} \cdot \mathrm{g}^{-1}$, where $S_{\text {BET }}$ is the Brunauer-Emmett-Teller surface area), presents only $95 \%$ decomposition after more than $40 \mathrm{~min}$.

As early as 1957 , Hauffman et a1. ${ }^{5}$ pointed out the effect of the microscopic roughness and porosity on the rate of dissolution of natural fluorapatite in dilute phosphoric acid. The authors reported that $S_{\text {BET }}$ of the natural sample increases as the reaction time increases. Dorozhkin ${ }^{6}$ reported that the crystal of the natural fluorapatite always dissolves in an acid medium with continuously increasing rates for all crystal faces.

Anbeek ${ }^{7}$ and Vaimakis et al. ${ }^{8}$ studied the relation ship between the surface roughness and the average grain diameter for various materials. Studying the hydrolysis of poly(ethylene terephthalate) (PET) powder in sulfuric acid, Yoshioka et al. ${ }^{9}$ assumed that the surface area is proportional to the degree of powder transformation. It may be noted that several previous investigations were focused on the variation of the surface area during the thermal decomposition or sintering of various solids. ${ }^{10} 11$ Zhang and Nater ${ }^{12}$ determined the BET-nitrogen surface areas of hornblende samples with increasing dissolution reaction time at $\mathrm{pH}=4$.

Although great progress was achieved in deriving a conceptual kinetic model for phosphate dissolution, ${ }^{4} 1314$ no attention was paid to the evolution of the surface and porosity of phosphate particles during reaction time. 


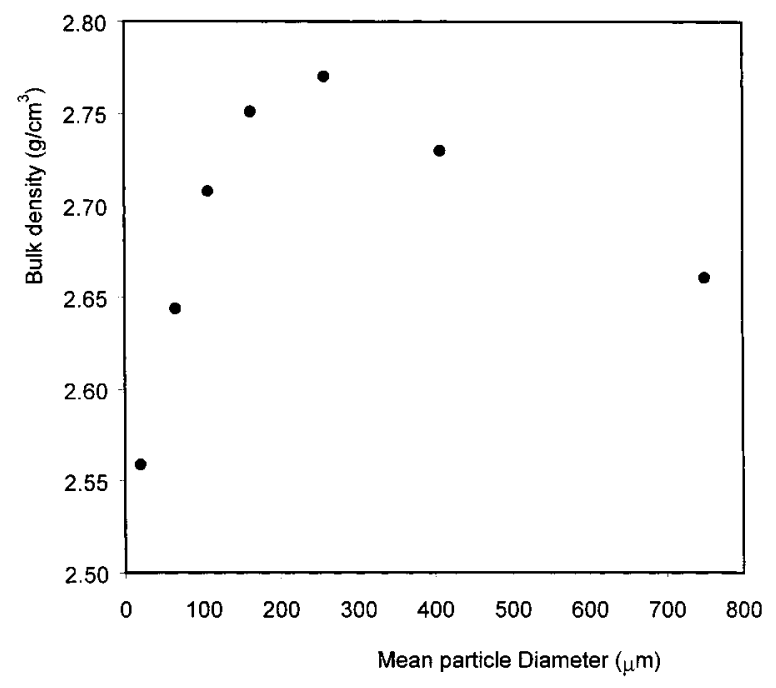

Figure 1. Variation of the bulk density with the average size of the phosphate particle.

This paper deals with the dissolution kinetics of one particle size fraction of raw phosphate into phosphoric solutions at $25{ }^{\circ} \mathrm{C}$. We were interested particularly on the relationships between the reaction progress and the physical properties of the solid residue. This was achieved by using solid-state chemical methods: scanning electron microcopy (SEM) and microanalysis, gas (argon) adsorption/desorption isotherms, mercury porosimetry, and helium density.

The comprehension of such variations is useful in phosphate fertilizer industries and mainly in the production of calcium superphosphate.

\section{Experimental Section}

The used raw material was provided from the Redeyef phosphate mines in Tunisia. The sample was sieved using ASTM standard sieves, and the particle size fraction used was +125 to $-200 \mu \mathrm{m}$; this fraction is that which presents the maximum bulk density (see Figure 1).

A total of $10 \mathrm{~g}$ of phosphate particles was placed into a glass reactor containing $0.5 \mathrm{~L}$ of $0.3 \mathrm{M} \mathrm{H}_{3} \mathrm{PO}_{4}$ prepared from chemical phosphoric acid $\left(85 \mathrm{mass}_{2} \mathrm{H}_{3} \mathrm{PO}_{4}\right)$. After different reaction times, the mixture was cooled rapidly and filtered through a 1G4 glass filter. The solid obtained at the end of each experiment was dried and weighed. The absolute densities of some solid samples, before and after dissolution, were measured by volume displacement using an Accupyc 1330 helium micrometric pycnometer. Specific surface areas were measured by argon adsorption at LN2 temperature $(77 \mathrm{~K}) \mathrm{using}$ the BET method. Before measurement, each sample was degassed at $100{ }^{\circ} \mathrm{C}$ for about $4 \mathrm{~h}$. The particle size distribution was measured by laser diffraction using a MasterSizer Malvern 2000 apparatus. Finally, the raw material, as well as the remaining solid collected, was photographed under appropriate magnifications using SEM. Chemical analysis was performed by spectrophotometric methods on a known quantity of residue dissolved in an $\mathrm{HCl}$ solution. So, for calcium, cadmium, and iron analysis, flame atomic absorption spectroscopy (FAAS) was used by employing an automated apparatus manufactured by Varian. However, phosphor as the $\mathrm{HPO}_{4}{ }^{2-}$ anion, $\mathrm{F}^{-}$, and $\mathrm{SO}_{4}{ }^{2-}$ were analyzed using a Dionex ion chromatograph with an IonPac AS12A

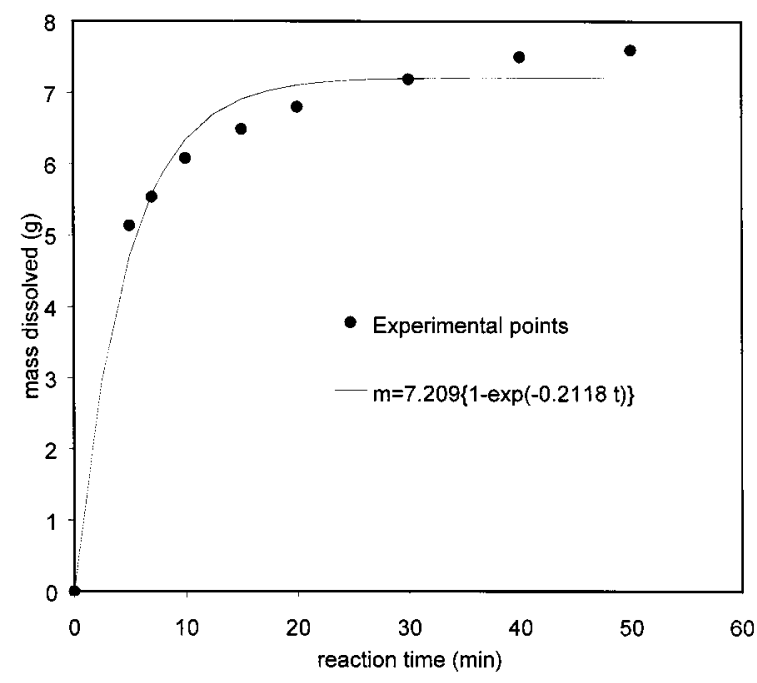

Figure 2. Dissolution kinetics of the phosphate fraction size $(125-200 \mu \mathrm{m})$ into $\mathrm{H}_{3} \mathrm{PO}_{4}(0.3 \mathrm{M})$ at $25{ }^{\circ} \mathrm{C}$.

Table 1. Chemical Analysis of the Phosphate Mineral Used in This Study

\begin{tabular}{cccc}
\hline component & $\begin{array}{c}\text { mass } \% \\
(\text { dry basis })\end{array}$ & component & $\begin{array}{c}\text { mass \% } \\
(\text { dry basis })\end{array}$ \\
\hline $\mathrm{P}_{2} \mathrm{O}_{5}$ & 27.90 & $\mathrm{SO}_{4}{ }^{2-}$ & 5.42 \\
$\mathrm{CaO}$ & 44.80 & $\mathrm{~F}^{-}$ & 3.16 \\
$\mathrm{Fe}_{2} \mathrm{O}_{3}$ & 0.245 & $\mathrm{CdS}$ & $137 \mathrm{ppm}$
\end{tabular}

Guard Plus analytical column. The chemical analysis of the original sample is seen in Table 1.

\section{Kinetic Curve $\alpha=f(t)$}

Figure 2 shows a typical dissolution curve that can be fitted empirically to an equation of the form

$$
m / m_{\infty}=1-\mathrm{e}^{-k t}
$$

where $m$ is the mass of phosphate dissolved at reaction time $t$ and $m_{\infty}$ is the final phosphate mass dissolved. The experimental data are well fitted by this equation. $k$ is the dissolution rate constant; it was found to be equal to $0.2118 \mathrm{~min}^{-1}$. It may be noted that the curve looks like first-order kinetics even though this kind of kinetics is observable for homogeneous systems where all of the reactant is involved during transformation, whereas in heterogeneous systems, only the compound at the surface can be dissolved. Such an equation has been used successfully by Kravtchenko et al. ${ }^{15}$ to describe the dissolution of pectin powder under dispersing conditions.

\section{Particle Size Distribution}

The particle size distribution of the remaining solid was determined using laser diffraction with water as a dispersant. In this aqueous medium, the mineral investigated does not present any solubility because it has been washed at first several times with water, so the particle size remains unchanged during the measurement. The differential size distribution of the initial sample $(t=0 \mathrm{~min})$ is given in Figure 3 . This figure shows that the mean particle diameter of the raw material obtained by the laser diffraction method is about $160 \mu \mathrm{m}$, not significantly different from that obtained by sieving $\left(d_{\mathrm{p}}=162.5 \mu \mathrm{m}\right)$. 


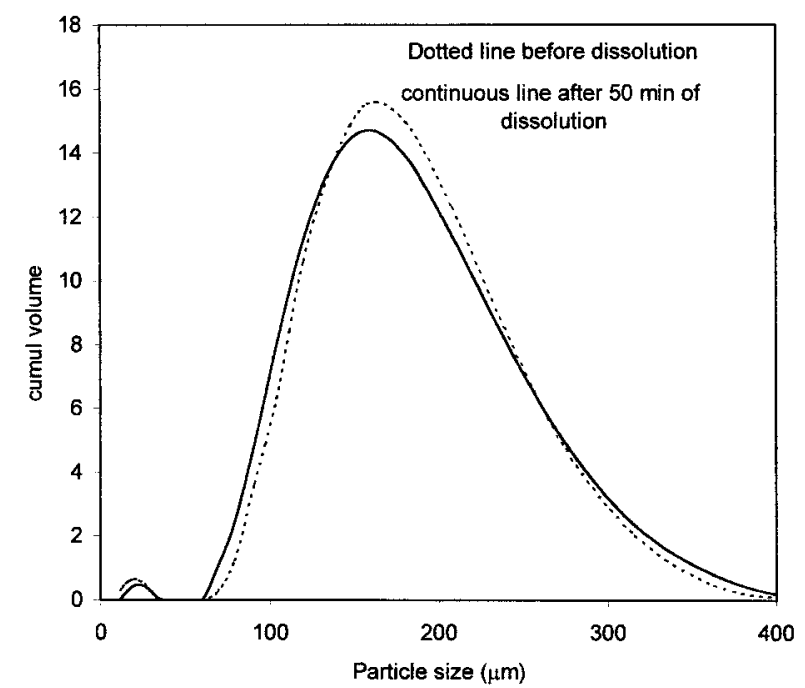

Figure 3. Size distribution for the reactant particles and particles after $50 \mathrm{~min}$ of dissolution.

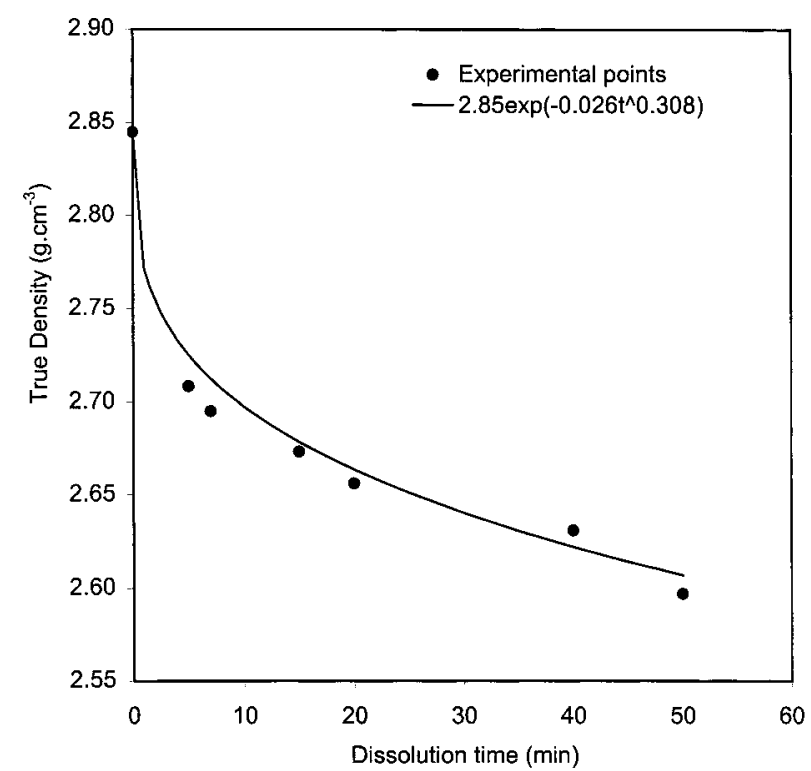

Figure 4. Variation of the true density of the solid versus the reaction time.

The particle size distribution obtained by the laser diffraction method (see Figure 3) presented a small fraction having a particle diameter of about $70 \mu \mathrm{m}$ and another fraction with a particle diameter of about 400 $\mu \mathrm{m}$. These last values are volume averages, whereas the sizes of the sieved particle fractions are related to the projected areas.

The second remark is that, although there was a large decrease in mass observed after 50 min of reaction, the two particle size distribution curves of the solids at $t=$ 0 and 50 min (see Figure 3 ) are almost superimposed, indicating that the mean diameter of the particles is not affected by the progress of the reaction. Moreover, Figure 3 shows a monomodal distribution indicating that all particles were submitted to the same sequences of states without disintegration.

\section{True Density}

Figure 4 shows the variation of absolute density as a function of dissolution time. The reproducibility of the

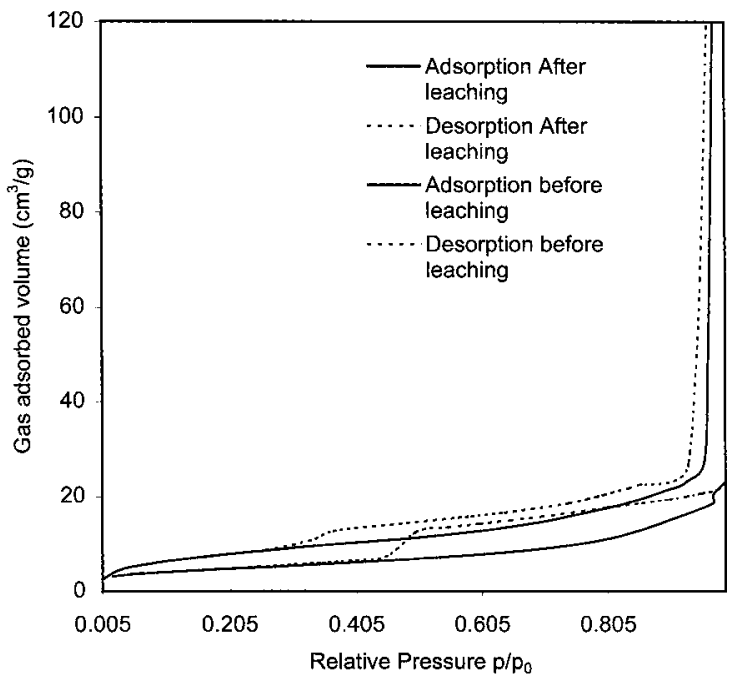

Figure 5. Argon adsorption and desorption isotherms for phosphate particles before and after $50 \mathrm{~min}$ of dissolution into $0.3 \mathrm{M}$ $\mathrm{H}_{3} \mathrm{PO}_{4}$ at $25^{\circ} \mathrm{C}$.

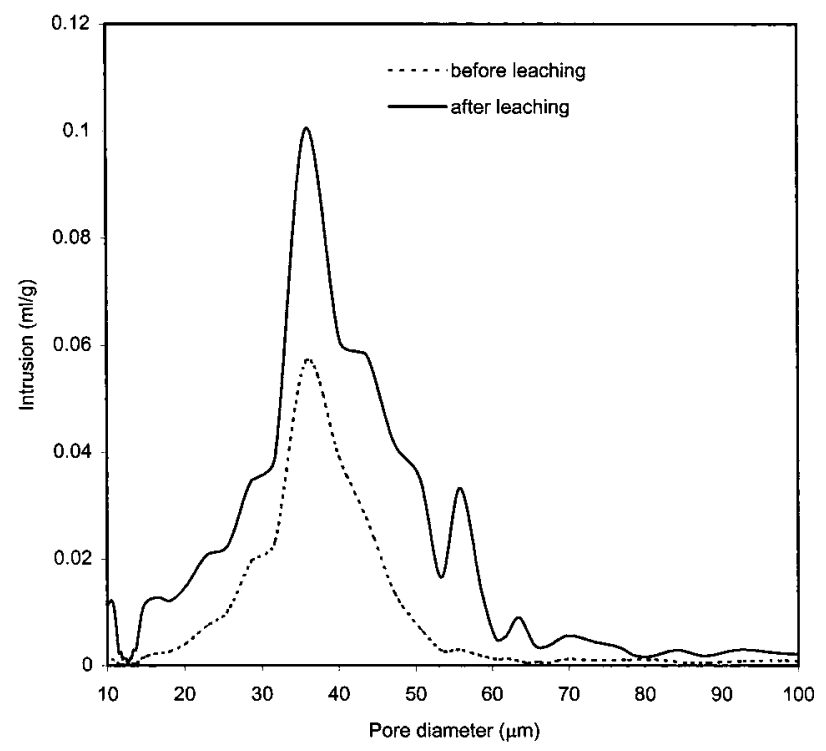

Figure 6. Logarithm of the differential intrusion versus the pore diameter for phosphate particles before and after $50 \mathrm{~min}$ of dissolution into $0.3 \mathrm{M} \mathrm{H}_{3} \mathrm{PO}_{4}$ at $25{ }^{\circ} \mathrm{C}$.

absolute density measurements with the Micromeritics Accupyc helium micrometric pycnometer is $\pm 0.1 \%$.

The true density decreases rapidly within a few minutes $(2-7 \mathrm{~min})$. Because the true density depends only on the nature of the phases existing in the system, the decrease indicates that the beginning of the reactions concerns some of the phases more than others. This suggests further investigation of the evolution of the porosity using gas adsorption/desorption and mercury intrusion.

From the beginning of the reaction up to about $7 \mathrm{~min}$, the decrease of the true density can be fitted using an empirical equation of the type

$$
\rho=\rho_{0}\left[\exp \left(-k t^{n}\right)\right]
$$

where $k$ and $n$ are constant, which can be determined using a nonlinear regression analysis. Probably the $k$ constant could depend on the mass $\% \mathrm{CaO}$ as a 


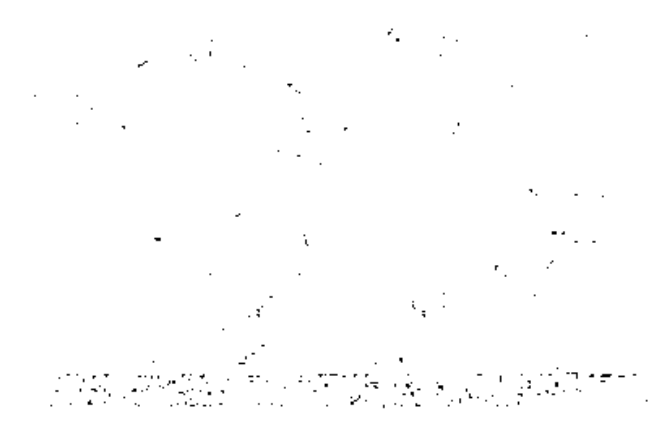

(Fig 7a) : Unreacted

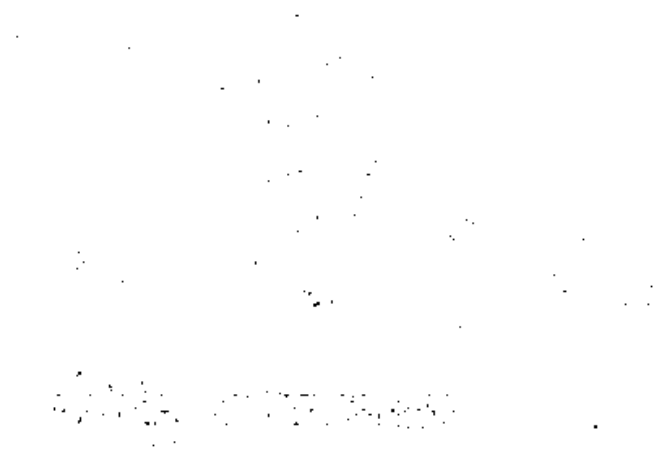

(Fig 7c) : After $10 \mathrm{~min}$ of dissolution

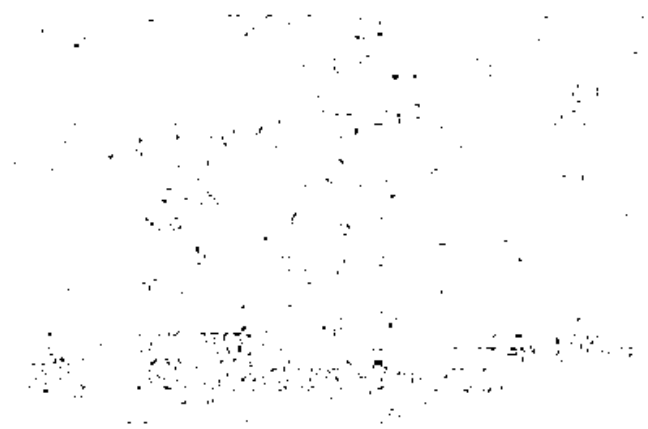

(Fig 7e) : After $50 \mathrm{~min}$ of dissolution

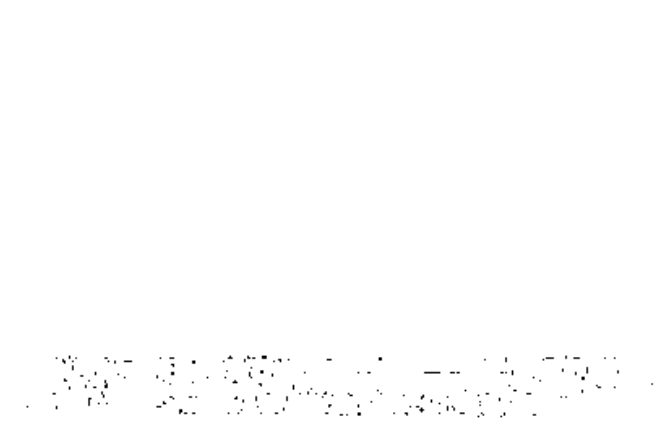

(Fig 7b) : After 5 min of dissolution

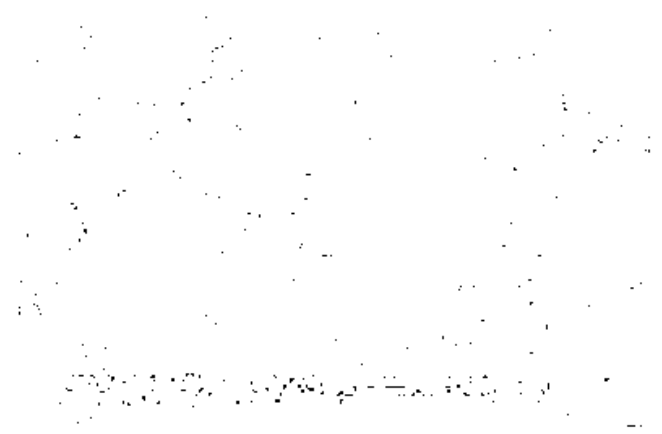

(Fig 7d) : After 20 min of dissolution

Figure 7. SEMs of phosphate particles: (a) unreacted; (b) after $5 \mathrm{~min}$; (c) after $10 \mathrm{~min}$; (d) after $20 \mathrm{~min}$; (e) after $50 \mathrm{~min}$.

parameter. Future investigation could elucidate this point.

\section{Surface Area and Adsorption/Desorption Isotherms}

Figure 5 shows the adsorption/desorption isotherms of the raw phosphate fraction $125-200 \mu \mathrm{m}$ and that of the leached one (after $50 \mathrm{~min}$ of dissolution). As was mentioned in our previous work, ${ }^{1}$ a hysteresis between adsorption and desorption was observed. This is a type IV isotherm according to the classification of the International Union of Pure and Applied Chemistry (IUPAC). ${ }^{16}$ The hysteresis type indicates the presence of the ink bottle pores. Table 2 reports a comparison of the gas porosimetric analysis of the samples at $t=0$ and $50 \mathrm{~min}$ of dissolution. In this table, we report three kinds of surface areas: The first is the surface area obtained using the BET method, the second represents
Table 2. Porosimetric Analysis of the Phosphate Fraction before and after Leaching

\begin{tabular}{|c|c|c|}
\hline & $\begin{array}{c}\text { before } \\
\text { dissolution }\end{array}$ & $\begin{array}{c}\text { after } \\
\text { dissolution }\end{array}$ \\
\hline \multicolumn{3}{|l|}{$\begin{array}{l}\text { size fraction } 125-200 \mu \mathrm{m} \\
\text { surface area }\left(\mathrm{m}^{2} \cdot \mathrm{g}^{-1}\right)\end{array}$} \\
\hline BET & 16.61 & 24.69 \\
\hline $\begin{array}{l}\text { at } p / p_{0}=0.319 \text { (before) and } \\
\text { at } p / p_{0}=0.167 \text { (after) }\end{array}$ & 16.56 & 23.36 \\
\hline $\begin{array}{l}t \text {-plot (external surface area) } \\
\text { pore volume }\left(\mathrm{cm}^{3} / \mathrm{g}\right)\end{array}$ & 16.06 & 27.60 \\
\hline $\begin{array}{l}\text { total for diameter }<2269 \\
\text { at } p / p_{0}=0.99\end{array}$ & 0.0316 & \\
\hline $\begin{array}{l}\text { total for diameter }<825 \\
\text { at } p / p_{0}=0.97\end{array}$ & & 0.220 \\
\hline pore size $(\AA)(4 \mathrm{~V} / \mathrm{A}$ by BET $)$ & 76 & 356 \\
\hline
\end{tabular}

the area when micropores are totally filled and the mesoporous and macroporous surfaces are just covered by a monomolecular argon layer, and the third is the external surface. The three kinds of areas as well as 


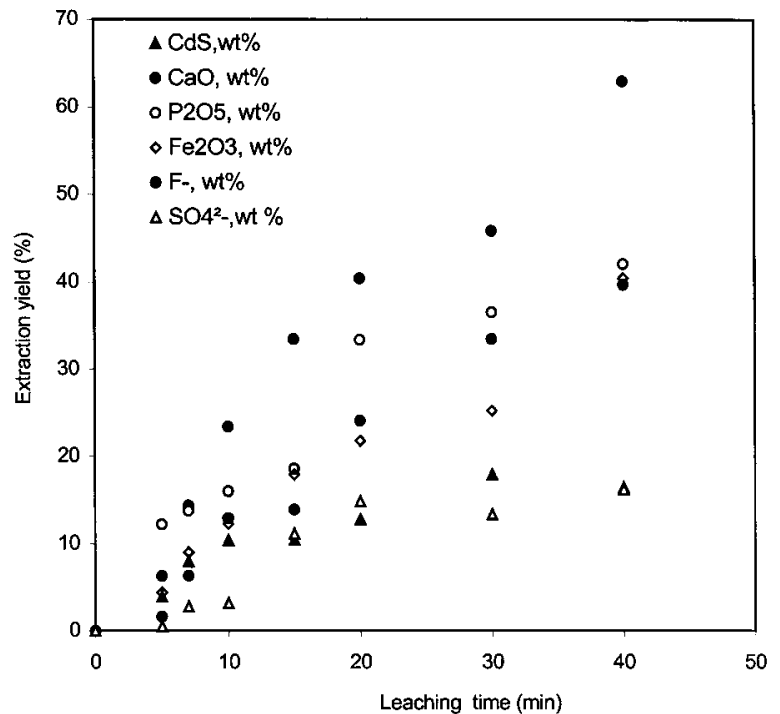

Figure 8. Profiles of the extent of dissolution of $\mathrm{CaO}, \mathrm{P}_{2} \mathrm{O}_{5}, \mathrm{CdS}$, $\mathrm{Fe}_{2} \mathrm{O}_{3}, \mathrm{SO}_{4}{ }^{2-}$, and $\mathrm{F}^{-}$against the reaction time.

the pore volume and the mean pore size are greater after 50 min of dissolution than before the reaction.
Hauffman et al..$^{5}$ reported that the specific surface areas of synthetic hydroxyapatite and fluorapatite increase as the dissolved fraction increases.

In our case, $S_{\text {BET }}$ decreases until the reaction time equals about $7 \mathrm{~min}$, and then it increases, reaching a value greater than the initial one. For example, after 7 min of reaction, the $S_{\text {BET }}$ value of the solid residue is $10 \mathrm{~m}^{2} \cdot \mathrm{g}^{-1}$ less than the in itial value $\left(16 \mathrm{~m}^{2} \cdot \mathrm{g}^{-1}\right)$, and it reaches $24 \mathrm{~m}^{2} \cdot \mathrm{g}^{-1}$ after $50 \mathrm{~min}$ of dissolution. We pointed out that the BET $C$ values obtained in this work are between 5 and 100 , confirming the validity of the BET model used to determine the specific surface area.

The decrease of $S_{\text {BET }}$ against the time of reaction can be attributed to the disappearance of roughness and the increase to the widening of pores.

Also, pore diameters from $1 \mathrm{~mm}$ down to $3 \mathrm{~nm}$ can be measured in a single analysis using mercury intrusion porosimetry. We reported in Figure 6 the specific intrusion volume $\left(\mathrm{mL} \cdot \mathrm{g}^{-1}\right)$ against the pore diameter $(\mu \mathrm{m})$. This figure shows that the pore diameter is concentrated at about $35 \mu \mathrm{m}$. This is probably due to the intragranular porosity. The average pore radius $(2 \mathrm{~V} /$ A) passes from 95 to $121.5 \mathrm{~nm}$ after $50 \mathrm{~min}$ of leach ing. The measured porosity was about $31 \%$ for the sample at $t=0 \mathrm{~min}$ and $53 \%$ at $t=50 \mathrm{~min}$ of dissolution. The

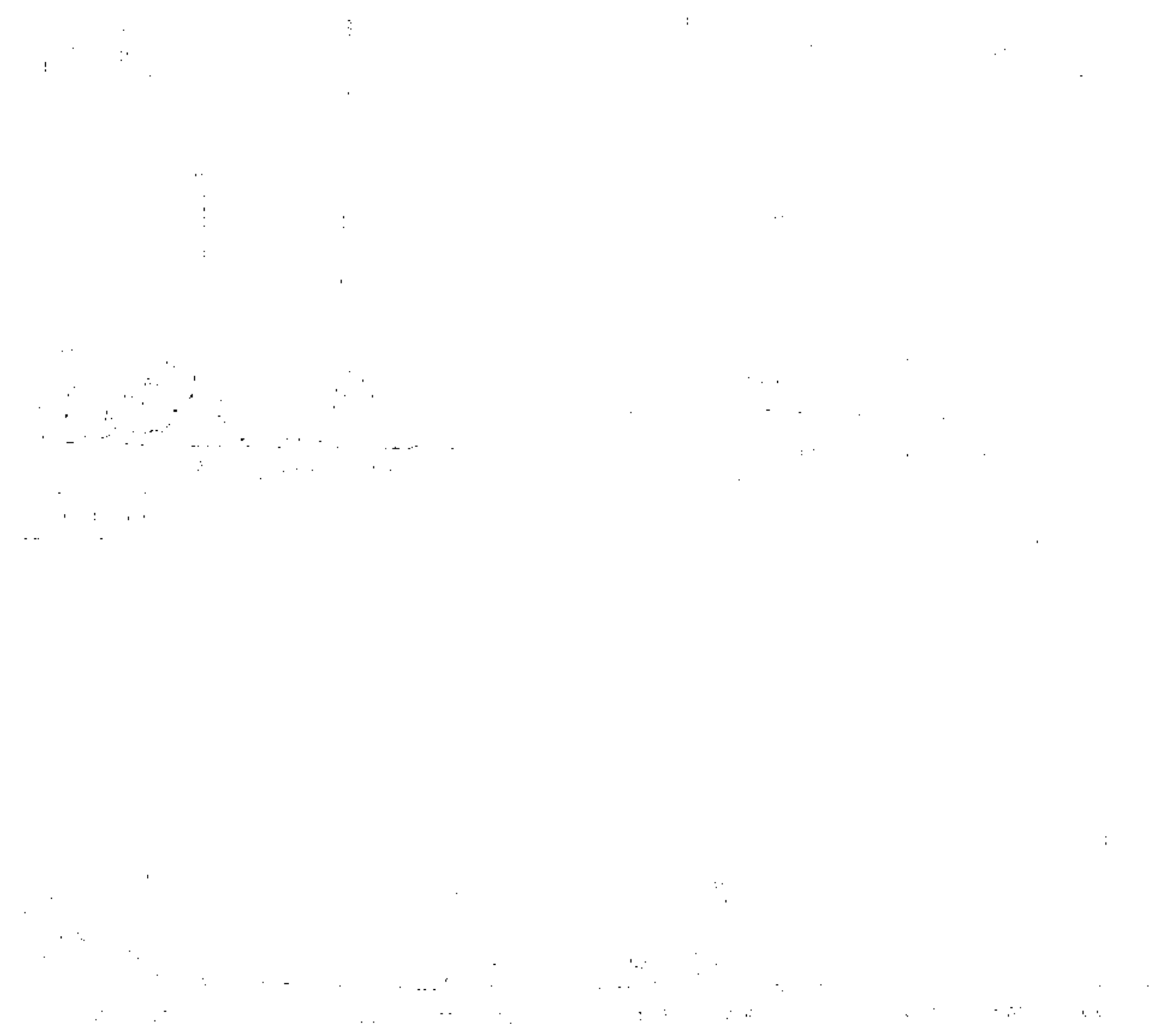


evolution of the pore diameter and porosity is in good agreement with the increase of the surface area.

\section{SEM Observations}

The SEM observations of the phosphates were performed using the following procedure: A certain amount of the sample was incorporated into resin, placed on the copper capsule, left to harden, and thin-sectioned (120 mesh).

SEM analysis (Figure 7a) reveals that all phosphate particles have the same ovoid shape. Each particle remains still ovoid up to $40 \mathrm{~min}$ of dissolution, and not all particles decrease their outer dimension. The dissolution seems to cause a widening of the pores until a partial fragmentation of the ore particle takes place.

Finally, it is important to point out that several mineral phases, of which apatite is the dominant phase, exist in the same phosphate particle. The uncertain distribution of the reactive phase (limestone and apatite) is probably a reason to explain the behavior observed during the phosphate particle dissolution. This leads us to investigate the evolution of the chemical composition of the liquid phase against the reaction time.

\section{Chemical Analysis of the Solution}

It is well-known that the solid investigated is a complex system containing apatite as the main phase besides lime, gypsum, cadmium sulfide, and iron oxide phases.

All of these minerals exhibit different behaviors toward dilute phosphoric acid. So, to explain the previous results, particularly the rise of the specific surface area and porosity with respect to the dissolution time, we investigate the evolution of the chemical composition of the remaining solid.

Figure 8 shows the extraction yield profiles expressed as $\mathrm{P}_{2} \mathrm{O}_{5}, \mathrm{CaO}, \mathrm{CdS}, \mathrm{Fe}_{2} \mathrm{O}_{3}, \mathrm{SO}_{4}{ }^{2-}$, and $\mathrm{F}^{-}$in the solution . The conversion fractions were calculated as follows:

$$
\mathrm{P}_{2} \mathrm{O}_{5} \%=\frac{m_{0} X_{0 \mathrm{P}_{2} \mathrm{O}_{5}}-m_{t} X_{t}, \mathrm{P}_{2} \mathrm{O}_{5}}{}
$$

where $m_{0}, X_{0 \mathrm{P}_{2} \mathrm{O}_{5}}$ and $m_{t}, X_{t \mathrm{P}_{2} \mathrm{O}_{5}}$ are the mass and $\mathrm{P}_{2} \mathrm{O}_{5}$ contents of the initial (at $t=0$ ) and remaining solid (at a time $t$ ), respectively.

We pointed out that the metal cations dissolved continuously during leaching and remained in an aqueous solution. No reprecipitation was observed; otherwise, an asymptotic level would be observed for the ion involved in the precipitate.

From this figure, it appears that at least $60-70 \%$ of calcium exists as a rapidly dissolvable phase, probably limestone in which the calcium is highly leachable. In Tunisian phosphate ore, about $80 \%$ of the calcium present in the particle is dissolved in $10 \mathrm{~min}$, but the time to achieve the maximum fluorine extraction is more than $1 \mathrm{~h}$ of dissolution $\left(B e c k e r^{4}\right)$.

As revealed by the electron diffraction analysis, carried out across the particles at different reaction times (see Figure 9), cadmium and iron ions were sometimes found to be associated with sulfur lattice and $\mathrm{F}^{-}$is related to the calcium lattice in the for $\mathrm{m}$ of $\mathrm{CaF}_{2}$. The presence of $\mathrm{Al}, \mathrm{Si}, \mathrm{S}, \mathrm{Na}$, and $\mathrm{Mg}$ was noted. We can conclude that there were three kinds of calcium: limestone, apatite, and calcium fluoride. Probably, the evolution of the texture of the phosphate particle depends on the chemical composition, notably the $\mathrm{CaO}$ content \% (i.e., $\mathrm{CO}_{2}$ ). Further investigations in our laboratory are in progress to highlight this behavior better.

\section{Conclusion}

The present work is an attempt to extend our knowledge about the phosphoric acid dissolution of natural phosphate rock. An empirical equation was proposed to describe the leaching rate. The rate constant $k$ was estimated at $0.2118 \mathrm{~min}^{-1}$. Porosimetric analysis of the particle size fraction $125-200 \mu \mathrm{m}$ before and after leaching was investigated, and the following conclusion s were drawn:

(a) Phosphate particles appear to be uniform in shape and size distribution and do not disintegrate during leaching.

(b) The variation of the true density of the solid residue can be expressed by an empirical equation of the form $\rho=\rho_{0}\left[\exp \left(-k t^{n}\right)\right]$.

(c) The pore structure study using nitrogen adsorption shows the ink bottle pores.

(d) The surface areas (BET and external) pass through a minimum at about $t=7 \mathrm{~min}$ to reach the value of 24 $\mathrm{m}^{2} \cdot \mathrm{g}^{-1}$ after $t=50 \mathrm{~min}$ by the disappearance of roughness and the widening of pores.

(e) According to electron diffraction analysis, cadmium and iron were found to exist in the sulfur lattice. Calcium exists such as apatite, calcite, and calcium fluoride.

\section{Literature Cited}

(1) Ben Brahim, F.; Mgaidi, A.; El Maaoui, M. Exploration of mesoporous structure of Tunisia raw and acid leached phosphate ore particles. Can. J. Chem. Eng. 1997, 75, Aug, 759-765.

(2) Ben Brahim, F.; Mgaidi, A.; El Maaoui, M. Kinetics of leaching of Tunisian phosphate ore particles in dilute phosphoric acid solutions. Can. J. Chem. Eng. 1999, 77, 136-142.

(3) Van der Sluis, S.; Meszaros, Y.; Marchee, W. G. J .; Wesselingh, H. A.; van Rosmalen, G. M. The digestion of phosphate ore in phosphoric acid. Ind. Eng. Chem. Res. 1987, 26, 25012505 .

(4) Becker, P. Phosphate and phosphoric acid; Fertilizer sciences and technology series 13; Marcel Dekker: New York, 1983.

(5) Hauffman, E. O.; Cate, W. E.; Deming, M. E.; Elmore, K. L. Rates of solution of calcium phosphate in phosphoric acid solutions. Agric. Food Chem. 1957, 5 (4), 266-275.

(6) Dorozhkin, S. V. Fundamentals of the wet-process phosphoric acid production. 1. Kinetics and mechanism of the phosphate rock dissolution. Ind. Eng. Chem. Res. 1996, 35, 43284335 .

(7) Anbeek, C. Change in surface area and dissolution rates during hornblende dissolution at pH 4.0. Geochim. Cosmochim. Acta 1994, 58 (No. 7), 1849-1850.

(8) Vaimakis, T. C.; Skordilis, C. S.; Pomonis, P. J . Alternation of geometrical and fractal dimensions of phosphate ore particles during grinding. J. Colloid Interface Sci. 1995, 172, $311-$ 316.

(9) Yoshioka, T.; Motoki, T.; Okuwaki, A. Kinetics of hydrolysis of poly(ethylene terephthalate) powder in sulfuric acid by a modified shrinking core model. Ind. Eng. Chem. Res. 2001, 40, $75-79$.

(10) Nicholson, D. Variation of surface area during the thermal decomposition of solids. Trans. Faraday Soc. 1965, 61, 990998.

(11) German, R. M.; Munir,Z. A. Surface Area reduction during isothermal sintering. J. Am . Chem. Soc. 1976, 59, 379-383. 
(12) Zhang, H.; Bloom, P. R.; Nater, E. A. Change in surface area and dissolution rates during hornblende dissolution at $\mathrm{pH}$ 4.0. Geochim . Cosmochim . Acta 1993, 57, 1681-1689.

(13) Slack, A. V. Phosphoric acid; Fertilizer sciences and technology series I; Marcel Dekker: New York, 1983.

(14) Abali, Y.; Sabri, C.; Yartasi, A. Dissolution kinetics of phosphate rock with $\mathrm{Cl}_{2}$ in water. Hydrometallurgy 1997, 46, 1325.

(15) Kravtchenko, T. P.; Renoir, J .; Parker, A.; Brigand, G. A novel method for determining the dissolution kinetics of hydrocolloid powders. Food Hydrocolloids 1999, 13, 219-225.
(16) IUPAC Reporting Physisorption data for Gas/Solid systems with special reference to the determination of surface area and porosity. Pure Appl. Chem . 1985, 57, 603-619. 